\title{
Supine and prone positions for percutaneous nephrolithotomy surgery: Comparison of experience of two different urology clinics
}

\section{Perkütan nefrolitotomi cerrahisinde supine ve prone pozisyon: İki farklı üroloji kliniğin deneyimlerinin karşılaştırılması}

\author{
Nurullah Hamidi, Erdem Öztürk, Taha Numan Yıkılmaz, Ali Fuat Atmaca, Halil Başar \\ ${ }^{1}$ Atatürk Eğitim ve Araștırma Hastanesi, Üroloji Bölümü, Ankara \\ ${ }^{2}$ Dr. Abdurrahman Yurtaslan Onkoloji Eğitim ve Araştırma Hastanesi, Üroloji Bölümü, Ankara \\ ${ }^{3}$ Ankara Yıldırım Beyazıt Üniversitesi Tıp Fakültesi, Üroloji Anabilim Dalı, Ankara
}

Dergiye Ulaşma Tarihi: 15.02.2018 Dergiye Kabul Tarihi: 28.02.2018 Doi: 10.5505/aot.2018.95867

\section{ÖZET}

GiRiş ve AMAÇ: Bu çalı̧̧mada iki farklı yüksek vaka sayılı üroloji kliniğinde iki farklı yöntemle yapılan perkütan nefrolitotomi(PNL) sonuçlarını karşılaştırmayı amaçladık.

YÖNTEM ve GEREÇLER: Kasım 2016- Kasım 2017 tarihleri arasında Ankara Dr. Abdurrahman Yurtaslan Onkoloji Eğitim ve Araştırma Hastanesi supine pozisyonda yapılan 45 PNL olgusu ile Ankara Atatürk Eğitim ve Araştırma Hastanesi Üroloji Kliniklerinde prone pozisyonda PNL yapılan 45 hastanın verileri retrospektif olarak değerlendirildi. Çalışmaya vücut dışı şok dalgası ile taş kırma tedavisi ve retrogradeintrarenal cerrahiye uygun olmayan taş boyutu $1.5 \mathrm{~cm}$ 'den büyük taş nedeniyle PNL yapılan hastalar çalışmaya dahil edildi.

BULGULAR: Her iki grup yaş, cinsiyet dağılımı, taşın olduğu taraf, taş lokalizasyonu, taş boyutu, taş volümü, parankim kalınlığı, taş dansitesi, giriş lokalizasyonu, fluroskopi süresi, kanama miktarı, nefrostomi kalış süresi ve hastanede kalış süresi özellikleri açısından istatistiksel olarak benzer idi. Nefrostomi takılma oranı supine PNL grubunda istatistiksel olarak anlamlı derecede daha yüksek idi $(\% 88,8$ 'e karş1 \%71,1, $\mathrm{p}=0,035)$. Buna karşlık double J stent takılma oranı prone PNL grubunda istatistiksel olarak anlamlı derecede daha yüksek idi (\%42,2'ye karş1 \%22,2, $\mathrm{p}=0,042)$. Toplam cerrahi süresi supine PNL grubunda istatistiksel olarak anlamlı derecede daha kısa idi $(\mathrm{p}=0,01)$. Perioperatif komplikasyon oranları karşılaştırıldığında komplikasyon izlenmeme oranı prone PNL grubunda istatistiksel olarak anlamlı derecede daha yüksek idi (\%82,2'ye karş1 $\% 68,9, \mathrm{p}=0,007)$.

TARTIŞMA ve SONUÇ: Böbrek taşlarının tedavisinde supine ve prone pozisyonlar benzer taşsızlık oranı, hastanede kalış süresi ve kanama oranlarına sahiptir. Prone pozisyonda yapılan PNL'ye göre supine pozisyonda yapılan PNL cerrahisi yaklaşık 15 dakika daha kısa sürmektedir. Ancak supine pozisyonda komplikasyon oranı nispeten daha fazladır.

Anahtar Kelimeler: Böbrek taşı, Perkütan nefrolitotomi, Prone, Supine

\begin{abstract}
INTRODUCTION: Introduction: In this study, we aimed to compare outcomes of two different percutaneous nephrolitotomy methods in two different high volume urology clinics.

METHODS: Data of 45 patients who underwent supine PNL in Ankara Dr. Abdurrahman Yurtaslan Oncology Training and Research hospital and 45 patients who underwent prone PNL in Ankara Atatürk Training and Research hospital were evaluated retrospectively. Patients who underwent PNL for $>1.5 \mathrm{~cm}$ renal stone and who unfit for extracorporeal shock wave lithotripsy and retrograde intrarenal surgery enrolled to this study.

RESULTS: Both groups are statistically similar in terms of age, gender, stone lateralization, stone localization, stone diameter, stone volume, renal parenchyme thickness, stone density, access localization, fluoroscopy time, bleeding, nephrostomy removal time and hospitalization time. Nephrostomy placement rate was statistically significant higher in supine PNL group ( $88.8 \%$ vs. $71.1 \%, \mathrm{p}=0.035)$. Incontrast, double $\mathrm{j}$ stent placement rate was statistically significant higher in prone PNL group $(42.2 \%$ vs. $22.2 \%, \mathrm{p}=0.042)$. Total surgery time was shorter in supine PNL group ( $\mathrm{p}=0.01)$. When perioperative complication rates compared, the rate of no complication was statistically higher in prone PNL group $(82.2 \%$ vs. $68.9 \%, \mathrm{p}=0.007)$.

DISCUSSION AND CONCLUSION: For treatment of kidney stones, supine and prone positions have similar stone free rates, hospitalization and bledding rates. According to prone position PNL, in supine position PNL surgery takes about 15 minutes shorter. However, complication rate is relatively higher in supine position.
\end{abstract}


Keywords: Kidney stone, Percutaneous nephrolitotomy, Prone, Supine

\section{GİRIŞ}

Güncel tedavi kılavuzlarına göre $20 \mathrm{~mm}$ 'den büyük veya kompleks böbrek taşlarında standart tedavi yöntemi Perkütan Nefrolitotomi (PNL)'dir (1,2). PNL cerrahisi ilk olarak 1976 yılında Fernstrom ve Johansson tarafindan tanımlanmıştır (3). Yapılan ilk PNL cerrahisi prone pozisyonda uygulanmıştır ve birçok klinik tarafından bu yöntem halen yaygın olarak uygulanmaktadır. Son y1llarda PNL cerrahisinin yaygınlaşması, gelişen teknoloji ve özellikle cerrahi aletlerin minyatürizasyonuile birlikte PNL tekniğinde yeni yaklaşımlar araştırılmıştır. Bu bağlamda supine pozisyonda PNL ilk defa 1987 yllında Valdivia ve arkadaşları tarafından literatüre kazandırılmıştır (4). Prone pozisyonda yapılan PNL cerrahilerinde pelvikalisyel sistemin görüntülenmesinin daha iyi ve çalışma alanının daha geniş olmasından dolayı majör organ yaralanma riski daha azdır (5). Ancak bu pozisyonda hastalar cerrahi süresince yüzüstü (prone pozisyonda) uzandıkları için anestezi sırasında akciğerlerin ventilasyon kapasitesi düşer ve buna bağlı olarak hastaların bir kısminda oksijenizasyon azalır. Ayrıca pronepozsiyon sirasinda yüksek ventilasyon basinc1 gelişmesi venöz geri dönüşü bozduğundan özellikle obez hastalarda kardiyo-pulmoner komplikasyon görülme riskini artırır (5).

Supine pozisyonda PNL 30 y1l önce tanımlanmış ve uzun süredir kullanılmasına karş1lık günümüzde birçok ürolog halen PNL yaparken prone pozisyonu tercih etmektedir (6). Ancak son y1llardasupinepozisyonda PNL yapılma sıklığı giderek artmaktadır. Şüphesiz ki supine PNL sıklığının artmasının en önemi nedenlerinden biri supine pozisyonunun PNL sırasında eşzamanlı olarak retrogradeintrarenal cerrahi yapılmasına da olanak kılmasıdır (7). Özellikle obez ve kronik akciğer hastalıkları olan hastalarda veya anteriorkaliks yerleşimli renal taşları olan hastalarda PNL yapılırken supine pozisyon tercih edilmektedir. Ayrica supine pozisyonda yapilan PNL sirasinda üreterkatateri yerleştirildikten sonra hastanın prone pozisyona çevrilemeyip aynı pozisyonda devam edilmesinin toplam cerrahi sürenin kısalmas1 üzerine anlamlı derecede etkisi vardır. Ayrica supine pozisyonda Access

Adress for correspondence: Atatürk Eğitim ve Araștırma Hastanesi Ankara - Türkiye e-mail: dr.nhamidi86@gmail.com

Available at www.actaoncologicaturcica.com

Copyright $\mathbb{C}$ Ankara Onkoloji Hastanesi sheath(k1lıf)'in pozisyonu irrigasyonmayinin ve kırılan taş parçalarının Access sheath (kılıf)' ten düşmesine yardımcı olur. Supin pozisyonun dezavatajları ise pelvikalisyel sistemde daha dar çalışma alanı olması ve ciltböbrek taşı mesafenin pronepoziyondakinden daha uzun olmasidır (7).

Bu çalışmada iki farklı yüksek vaka sayılı üroloji kliniğinde iki farklı yöntemle yapılan PNL sonuçlarını karşılaştırmayı amaçladık.

\section{GEREÇ ve YÖNTEM}

Kasım 2016- Kasım 2017 tarihleri arasında Ankara Dr. Abdurrahman Yurtaslan Onkoloji Eğitim ve Araştırma Hastanesi Üroloji Kliniğinde supine pozisyonda PNL yapılan 45 hastanın verileri retrospektif olarak değerlendirildi. Bu hastaları karşılaştırmak için aynı tarihler arasında Ankara Atatürk Eğitim ve Araştırma Hastanesinde prone pozisyonda PNL yapılan 136 hastanın içinden ardışık 45 hastanın verileri de incelendi. Çalışmaya vücut dışı şok dalgası ile taş kırma tedavisi ve retrogradeintrarenal cerrahiye uygun olmayan taş boyutu $1.5 \mathrm{~cm}$ 'den büyük taş nedeniyle PNL yapılan hastalar çalışmaya dahil edildi.

Tüm hastalarda tam kan sayımı, serum biyokimya (Kreatinin, kan üre azotu, sodyum, potasyum, glomerulerfiltrasyon değeri), tam idrar tahlili ve idrar kültürü bakıldı. PNL yapılan tüm hastalarda idrar tahlili ve kültüründe üreme olmadığından emin olundu. Taş boyutu, taş lokalizasyonu, taş dansitesi (HounsefieldUnit), böbrek parankim yapısı, böbrek kaliks anatomisi ve giriş traktının belirlenmesi için tüm hastalar PNL öncesi kontrastsız bilgisayarlı tomografi ile değerlendirildi. Taş boyutları kaydedilirken hem en uzun çap $(\mathrm{mm})$ hem de 3 boyutlu ölçümler $\left(\mathrm{mm}^{3}\right)$ kaydedildi. Toplam cerrahi süresi; hastanın uyutulmasının tamamlanması ile PNL prosedürünün tamamlanması arasında geçen süre kabul edildi.

\section{Perkütan Nefrolitotomi prosedürleri}

Tüm PNL prosedürleri genel anestezi altında yapıldı. Supine PNL prosedürü için ModifiyeValdivia pozisyonu kullanıldı. 
Üreterkatateri (5F) aynı pozisyonda takıld1. Prone PNL sirasinda ise üreterkataterilitotomi pozisyonunda takıldı. Ardından hastalara prone pozisyon verildi. Tüm hastalarda kaliks girişleri fluroskopialtında yapıldı. Giriş traktları 30 F'e kadar dilate edildi. Ardından amplatz eşliğinde nefroskop (Karl Storz, Tuttlingen, Germany) girişi yapıldı. Taşlar pnömotiklitotriptör(Elmed, Ankara, Turkey) kullanılarak fragmante edildi. PNL işlemi tamamlandıktan sonra cerrahın tercihine göre nefrostomi tüpü yerleştirildi. Rezidü taş fragmanları kalan veya komplikasyon gelişen olgularda üreteredouble $\mathrm{J}(6 \mathrm{~F}, 26 \mathrm{~cm})$ stent yerleştirildi.

PNL işlemi tamamlandıktan sonra 2 saat içerisinde hastalarda tam kan sayımı ve serum biyokimya çalışıldı. Operasyondan 1 gün sonra tüm hastalara direkt üriner sistem grafisi çekildi. Onbirinci kot üzerinden giriş yapılan hastalarda pnömotoraks1 ekarte etmek için direkt üriner sistem grafisine ek olarak akciğer grafisi de çekildi.

Nefrostomi tüpü takilan hastalardanefrostomi;nefrostomiden gelen idrar vasfı, miktarı ve hastanın ağrısına göre hastaneden taburcu olmadan önce çekildi. Üretere takılan Double $\mathrm{j}$ stentler PNL işleminden 4 hafta sonra alındı. Double J stent alınmadan önce tüm hastalar rezidü taş açısından tekrar değerlendirildi. Taşları opak olan hastalar direkt üriner sistem grafisi ile değerlendirilirken taşları opak olmayan hastalar ise kontrastsiz bilgisayarlı tomografi ile değerlendirildi. Dört mm'den daha büyük taş fragmanları rezidü taş olarak kabul edildi. Ayrıca PNL sırasında ve sonrasında gelişen komplikasyonlar, kanama miktarı, eritrosit transfüzyon oranları kaydedildi. Kanama miktarı $\mathrm{Hb}_{\mathrm{PNL}}$ öncesi $-\mathrm{Hb}_{\mathrm{PNL} \text { sonrası }}$ formülüne göre hesaplandi. Komplikasyonlar modifiyeClavien-Dindo siniflamasına göre kaydedildi.

\section{İstatistiksel analiz}

Tüm istatistiksel analiz için SPSS 16.0 (IBM Company Chicago, Illinois, ABD) program kullanıldı. Değişkenlerin normal dağılım gösterip göstermediği Kolmogorov-Smirnow testi ile değerlendirildi. İki grup arasında normal dağılım varsayımını sağlayan gösteren bağımsız değişkenlerin karşılaştırmalarında Student t ve Ki-Kare testleri, normal dağılım

Adress for correspondence: Atatürk Eğitim ve Araş̧ırma Hastanesi Ankara - Türkiye e-mail: dr.nhamidi86@gmail.com

Copyright (Ankara Onkoloji Hastanesi göstermeyen bağımsız değişkenlerin karşılaştırılmasında ise Mann-Whitney $\mathrm{U}$ testi kullanıldı. $p$ değerinin 0,05 'ten küçük olduğu değerler istatistiksel olarak anlamlı kabul edildi.

\section{SONUÇLAR}

Tüm hastalarımızın (40 kadın, 50 erkek) ortalama yaş1 $49 \pm 13$ y1l, ortalama vücut kitle endeksi (VKI) $25,8 \pm 4,3 \mathrm{~kg} / \mathrm{m}^{2}$ idi. Taşların $\% 45,7$ 'si renalpelviste yerleşirken, $\% 44,4$ 'ü alt kalikste, \%6,6's1 orta kaliks ve \%3,3'ü üst kaliks yerleşimli idi. Ortalama parankim kalınlığı ve en uzun taş boyutu $13,3 \pm 2 \mathrm{~mm}$, $22,9 \pm 6 \mathrm{~mm}$ idi. Ortanca taş volümü ve ortanca taş dansitesi sırasıyla 3240 (min:755 maks:16020) $\mathrm{mm}^{3}$ ve 1120 (min: 431 maks: 2250) HU idi. İşlem bitiminde hastaların 72'sine (\%80) nefrostomi tak1ld. Ayn1 zamanda hastaların 29'una $(\% 32,2)$ double J stent takıld1. Hastalarımızda toplam cerrahi ve toplam fluroskopi süresi sirasiyla $84 \pm 26$ ve $5 \pm 1$ dakika idi. Ortalama kanama miktarı $2,3 \pm 0,8 \mathrm{mg} / \mathrm{dL}$ idi.

Hastaların 68 'inde $(\% 75,6)$ operasyon sirasinda ve sonrasinda herhangi bir komplikasyon izlenmezken, 14'ünde $(\% 15,6)$ clavien komplikasyon sinıflamasına göre grade I, 8 'inde $(\% 8,8)$ grade II komplikasyon izlendi. Ortalama nefrostomi kalış süresi ve hastanede kalış süresi sırasıyla $1,8 \pm 0,4$ ve $3 \pm 1,7$ gün idi. Hastalarımızın 63'ünde(\%70) PNL'den 1 ay sonra yapilan kontrollerinde rezidü taş izlenmedi. Tüm veriler tablo 1'de ayrintıl1 olarak gösterildi.

Her iki grup ortalama yaş, cinsiyet dağılımı, VKI, taşın olduğu taraf, taş lokalizasyonu, ortalama taş boyutu (mm), ortanca taş volümü $\left(\mathrm{mm}^{3}\right)$, parankim kalınlığ , ortanca taş dansitesi, giriş lokalizasyonu, fluroskopi süresi, kanama miktarı, nefrostomi süresi ve hastanede kalış süresi özellikleri açısından istatistiksel olarak benzer idi.

Nefrostomi takılma oranı supine PNL grubunda istatistiksel olarak anlamlı derecede daha yüksek idi (\%88,8'e karş1 \%71,1, $\mathrm{p}=0,035)$. Buna karş11ı double J stent takılma oran1 prone PNL grubunda istatistiksel olarak anlaml derecede daha yüksek idi (\%42,2'ye karş1 \%22,2, $\mathrm{p}=0,042)$. Toplam cerrahi süresi supine PNL gurubunda istatistiksel olarak anlamlı derecede daha kisa idi $(p=0,01)$. Perioperatif komplikasyon oranlar1 
karşılaştırıldı̆̆ında komplikasyon izlenmeme oranı prone PNL gurubunda istatistiksel olarak anlamlı derecede daha yüksek idi (\%82,2'ye karş1 \%68,9, p=0,007). Tüm karş1laştırmalar tablo 1'de ayrintıl1 olarak verildi.

Tablo 1. Hastaların genel özellikleri ve her iki grubun karşılaştırılması

\begin{tabular}{|c|c|c|c|c|}
\hline Parametreler & Tüm hastalar & $\begin{array}{l}\text { Supine } \quad \text { PNL } \\
(n=45)\end{array}$ & $\begin{array}{ll}\text { Prone } & \text { PNL } \\
(n=45) & \end{array}$ & $p$ \\
\hline Yaş (yll), ortalama $\pm S S$ & $49 \pm 13(26-69)$ & $50 \pm 11(29-63)$ & $48 \pm 13(26-69)$ & ${ }^{\mathrm{a}} 0,2$ \\
\hline Cinsiyet, n (\%) & & & & ${ }^{\mathrm{b}} 0,67$ \\
\hline Kadın & $40(44,4)$ & $21(46,6)$ & $19(42,2)$ & \\
\hline Erkek & $50(55,6)$ & $24(53,4)$ & $26(57,8)$ & \\
\hline VKI $\left(\mathrm{kg} / \mathrm{m}^{2}\right)$, ortalama $\pm \mathrm{SS}$ & $25,8 \pm 4,3(21,5-33,5)$ & $\begin{array}{l}26,6 \pm 3,8 \quad(22,5- \\
33,5)\end{array}$ & $\begin{array}{l}24,9 \pm 4,1 \quad(21,3- \\
31)\end{array}$ & ${ }^{\mathrm{a}} 0,65$ \\
\hline Taşın olduğu taraf, n (\%) & & & & ${ }^{\mathrm{b}} 0,83$ \\
\hline Sol & $43(47,7)$ & $21(46,6)$ & $22(48,8)$ & \\
\hline Sağ & $47(52,3)$ & $24(53,4)$ & $23(51,2)$ & \\
\hline Taş lokalizasyonu, n (\%) & & & & $\begin{array}{l}\mathrm{b} 0,6 \\
0,6\end{array}$ \\
\hline Alt kaliks & $40(44,4)$ & $17(37,8)$ & $23(51,1)$ & \\
\hline Orta kaliks & $6(6,6)$ & $3(6,7)$ & $3(6,7)$ & \\
\hline Üst kaliks & $3(3,3)$ & $2(4,4)$ & $1(2,2)$ & \\
\hline Renal pelvis & $41(45,7)$ & $23(51,1)$ & $18(40)$ & \\
\hline $\begin{array}{lll}\text { Parankim } & \text { kalınlığı } & (\mathrm{mm}), \\
\text { ortalama } \pm \text { SS } & & \\
\end{array}$ & $13,3 \pm 2(10-16)$ & $13,5 \pm 2(10-16)$ & $13 \pm 3(10-15)$ & ${ }^{\mathrm{a}} 0,74$ \\
\hline $\begin{array}{l}\text { En uzun taş boyutu }(\mathrm{mm}) \text {, } \\
\text { ortalama } \pm \text { SS }\end{array}$ & $22,9 \pm 6(16-36)$ & $22,6 \pm 4,7(16-25)$ & $23,3 \pm 5,7(18-36)$ & ${ }^{\mathrm{a}} 0,1$ \\
\hline $\begin{array}{l}\text { Taş volümü }\left(\mathrm{mm}^{3}\right) \text {, ortanca }(\min - \\
\text { maks) }\end{array}$ & $3240(755-16020)$ & $3140(755-14951)$ & $3280(800-16020)$ & ${ }^{\mathrm{c}} 0,12$ \\
\hline $\begin{array}{l}\text { Taş dansitesi (HU), ortanca (min- } \\
\text { maks) }\end{array}$ & $1120(431-2250)$ & $1060(431-2250)$ & $1280(464-2100)$ & ${ }^{\mathrm{c}} 0,3$ \\
\hline Giriş lokalizasyonu, n(\%) & & & & ${ }^{\mathrm{b}} 0,75$ \\
\hline Subkostal (12.kot altı) & $80(88,8)$ & $41(91,1)$ & $39(86,7)$ & \\
\hline 12. kosta üstü & $8(8,8)$ & $3(6,6)$ & $5(11,1)$ & \\
\hline 11. kosta üstü & $2(2,4)$ & $1(2,3)$ & $1(2,2)$ & \\
\hline Nefrostomi takılma oranı, $\mathbf{n}(\%)$ & $72(80)$ & $40(88,8)$ & $32(71,1)$ & ${ }^{\mathrm{b}} 0,035$ \\
\hline $\begin{array}{l}\text { Double J stent takılma oranı, n } \\
\text { (\%) }\end{array}$ & $29(32,2)$ & $10(22,2)$ & $19(42,2)$ & ${ }^{\mathrm{b}} 0,042$ \\
\hline Toplam cerrahi süresi $(\mathbf{d k})$, & $84 \pm 26(55-120)$ & $78 \pm 18(60-105)$ & $91 \pm 25(55-120)$ & ${ }^{\mathrm{a}} 0,01$ \\
\hline
\end{tabular}




\begin{tabular}{|c|c|c|c|c|}
\hline ortalama $\pm S S$ & & & & \\
\hline $\begin{array}{lll}\text { Fluroskopi } & \text { süresi } & (\text { dk }), \\
\text { ortalama } \pm S S & & \end{array}$ & $5 \pm 1(3-11)$ & $4,8 \pm 0,7(3-5)$ & $5,2 \pm 1,2(3-11)$ & ${ }^{\mathrm{a}} 0,07$ \\
\hline $\begin{array}{l}\text { Kanama miktarı (Hb düşüşü, } \\
\text { mg/dL), ortalama } \pm \text { SS }\end{array}$ & $2,3 \pm 0,8(1,1-4,5)$ & $2,4 \pm 0,8(1,6-4,5)$ & $2,1 \pm 0,9(1,1-3)$ & ${ }^{\mathrm{a}} 0,34$ \\
\hline $\begin{array}{l}\text { Eritrosit transfüzyon varlığı, n } \\
(\%)\end{array}$ & $3(3,3)$ & $2(4,4)$ & $1(2,2)$ & ${ }^{\mathrm{b}} 0,61$ \\
\hline Taşsızlık oranı, n (\%) & $63(70)$ & $30(66,7)$ & $33(\% 73,3)$ & b 0,48 \\
\hline Perioperatif komplikasyon, n (\%) & & & & ${ }^{\mathrm{b}} 0,007$ \\
\hline Komplikasyon izlenmedi & $68(75,6)$ & $31(68,9)$ & $37(82,2)$ & \\
\hline Clavien Grade I & $14(15,6)$ & $8(17,7)$ & $6(13,3)$ & \\
\hline -Yüksek ateş $\left(>38.3^{\circ} \mathrm{C}\right)$ & $6(6,6)$ & $3(6,6)$ & $3(6,6)$ & \\
\hline -Kreatinin yüksekliği & $8(8,8)$ & $5(11,1)$ & $3(6,6)$ & \\
\hline Clavien Grade II & $8(8,8)$ & $6(13,3)$ & $2(4,4)$ & \\
\hline transfüzyonu & $3(3,3)$ & $2(4,4)$ & $1(2,2)$ & \\
\hline $\begin{array}{l}\text { gerektiren kanama } \\
\text {-İdrar yolu enfeksiyonu }\end{array}$ & $5(5,5)$ & $4(8,9)$ & $1(2,2)$ & \\
\hline $\begin{array}{lll}\text { Nefrostomi } & \text { kalış } & \text { süresi(gün), } \\
\text { ortalama } \pm S S & & \end{array}$ & $1,8 \pm 0,4(1-4)$ & $1,7 \pm 0,3(1-2)$ & $1,9 \pm 0,4(1-4)$ & ${ }^{\mathrm{a}} 0,5$ \\
\hline $\begin{array}{l}\text { Hastanede kalış süresi (gün), } \\
\text { ortalama } \pm \text { SS }\end{array}$ & $3 \pm 1,7(2-10)$ & $3,1 \pm 1,9(2-6)$ & $3 \pm 1,5(2-10)$ & ${ }^{\mathrm{a}} 0,39$ \\
\hline
\end{tabular}

BMI, Body mass index(Vücut kitle indeksi); HU, Hounsefield Unit; PNL, Perkütan nefrolitotomi; SD, Standart sapma

${ }^{\text {aStudent }} \mathrm{t}$ test ile karşılaştırıldı

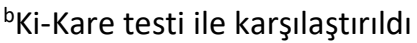

'MannWhitney U testi ile karşılaştırıldı

\section{TARTIŞMA}

Vücut dışı şok dalgası ile taş kırma tedavisi ve retrogradeintrarenal cerrahiye uygun olmayan taş boyutu büyük $(>15 \mathrm{~mm})$ olan hastalarda kılavuzlarca önerilen altın standart tedavi PNL' dir (1,2). Bu cerrahide elde edilen taşsızlık oranı vücut dışı şok dalgası ile taş kırma tedavisi ve retrogradeintrarenal cerrahiye göre daha yüksektir $(1,2)$. Bugün için ülkemizde ve dünyada birçok merkezde PNL işlemi prone pozisyonda yapılmaktadır. Prone pozisyonun daha fazla tercih edilmesinin sebebi ürologların supine pozisyona alışkın olmamaları ve buna bağlı olarak tecrübelerinin az oluşudur.

Bugün için güncel meta-analizlerde supine ve prone PNL arasında cerrahinin başarı (taşsızlık oranı) oranı açısından anlamlı farklılık olmadiğına dair kanitlar bulunmaktadır (8-12). Bunu aksini iddia eden çalışmalarda bulunmaktadır. Çok merkezli (CROES çalışması) bir çalışmada; prone pozisyonda yapilan PNL hastalarında supine pozisyonda yapilan hastalara göre operasyon sonrasında daha iyi taşsızlık oranlarının olduğu raporlanmıştır (\%59'e karş1 \%48, p<0.001) (12). CROES çalışmasına katılan klinik sayısı oldukça yüksek (96 merkez) olmasına rağmen klinik başına düşen hasta sayısı oldukça düşüktür (ortalama 27 hasta) (12). Bu da ister istemez cerrahların supinePNL tecrübesini sorgulamaya yönelmektedir. Ayrıca PNL işlemlerini yapan birden fazla cerrahın tecrübe düzeyinin farklı olması bu sonuçlara sebep olabilir. Ülkemizde 39 supine PNL ile 48 prone PNL hastasının karşılaştıııldığ 1 bir 
çalışmada ise staghorn böbrek taşının bulunduğu hastalarda her iki PNL tekniğinin eşit taşsızlık oranlarına (supine PNL grubunda $\% 64$, prone PNL grubunda \%60, $\mathrm{p}=0.72$ ) sahip olduğu vurgulanmıştır (8). Burada dikkat çekici önemli nokta tüm PNL işlemlerinin tek cerrah tarafından yapılmış olmasıdır. İki bin on alt1 y1lında yayınlanan 6881 hastanın verisinin incelendiği güncel bir meta-analizde ise prone pozisyonda yapılan PNL hastalarında istatistiksel olarak anlaml derecede daha yüksek taşsızlık oranları raporlanmıştır (\%77'e karşı \% 74, p<0.001) (9). Çalışmamızda prone pozisyonda yapılan PNL hastalarında taşsızlık oranı supine pozisyonda yapılan hastalara göre daha yüksek (\%73,3'e karş1 \%66,7) olmasına karşılık bu fark istatistiksel olarak anlamlı değildi $(\mathrm{p}=0,49)$.

Prone pozisyonda PNL yapilırken hastaya önce supinepozsiyondaüreterkatateri takıldığ 1 sonra hastanın pronepozsiyona çevrildiği için önemli miktarda vakit kaybedilmektedir. Supine pozisyonda yapilan PNL işlemi sırasında hastada pozisyon değişikliği yapılmadığ 1 için bu vakit kaybı genelde olmamaktadır. Güncel bir randomize kontrollü çalışmada prone pozisyonda PNL yapilan hastalarda ortalam cerrahi süresi 111 dakika iken bu süre supine pozisyonda PNL yapılan hastalarda 86 dakika idi (13). Yuan ve arkadaşlarının yayınladığı 13 yayının derlendiği çalışmada ise supine pozisyonda PNL yapilan hastalarda cerrahi süresinin daha kısa olduğu raporlanmıştır (11). Buna karşın 20 çalışmanın derlendiği başka bir metaanalizde prone pozisyonun toplam PNL süresini uzatmadığı bildirilmiştir (10). Çalışmamızda mevcut yayınların çoğunu destekler nitelikte supine pozisyonda yapılan PNL hastalarında ortalama cerrahi süresi 78 dakika iken, supine pozisyonda yapılan PNL hastalarında bu süre 91 dakika idi. Prone pozisyonda cerrahi süresinin daha uzun çıkmasının bir nedeni de prone pozisyonda yapılan PNL hastalarında double J stent takma oranı supine pozisyonda yapilan PNL hastalarına göre daha yüksek olmasıdır (\%42,2' ye karşı \%22). Klinik tecrübemize göre double $\mathrm{J}$ stent takılması toplam cerrahi süresini yaklaşık 5-10 dakika uzatmaktadır.

Prone pozisyonda yapilan PNL işleminde hasta supine pozisyonda entübe edildikten sonra cerrahi işlem süresi boyunca prone pozisyonda kalmaktadır. $\mathrm{Bu}$ da akciğerlerin ventilasyonunu kısitlamakta ve dolayısıyla oksijen satürizasyonu ile ilgili problemlere yol açmaktadır. Birçok ürolog PNL planlanan hastalarda böbreğe yakın seyreden ve giriş traktı üzerinde herhangi bir barsak veya kolon ansı bulunup bulunmadığını genellikle bilgisayarlı tomografi ile kontrol etmektedir. Bilindiği üzere bilgisayarlı tomografide görüntüler hasta supine pozisyonda iken alınır. $\mathrm{Bu}$ pozisyonda hastaların bağırsakları böbreklerden daha uzakta yerleşir. Ancak hastalar klasik PNL pozisyonu olan prone pozisyona alındıklarında barsaklarınretroperitona daha çok yaklaşması beklenir. $\mathrm{Bu}$ görüş klinik çalışmalarca da desteklenmiştir. Sharma ve ark. (14) yaptıkları çalışmada supine pozisyonda çekilen bilgisayarlı tomografide retrokolon görülme ihtimali \%2 iken, bu risk prone pozisyonda çekilen bilgisayarlı tomografide $\% 6,8$ dir. Bir diğer çalışmada PNL için oblik olarak giriş yapıldığ 1 takdirde kolon hasarı riski supine pozisyonda $\% 0$ iken, prone pozisyonda bu riskin $\% 3$ olduğunu belirtmişlerdir (15). Ancak mevcut güncel serili klinik çalışmalarda kolon yaralanma riskinin her iki pozisyonda da istatistiksel olarak benzer olduğu bildirilmektedir (supine ve prone pozisyonda sirasiyla $\% 3,4$ ve $\% 3,3, \quad \mathrm{p}=0,958$ ) (6). Çalışmamızda bağırsak, dalak ve karaciğer gibi herhangi bir organ hasarı görülmemiştir. Çalışmamızda her iki grupta da görülen komplikasyonlar PNL sonrası görülen yüksek ateş, operasyon sonrası erken dönemde görülen kreatininyükssekliği, idrar yolu enfeksiyonu ve transfüzyon gerektiren kanama idi. Clavien siniflamasina göre her iki grup karşılaştırıldığında komplikasyon görülmeyen hastaların oranı prone pozisyonda PNL yapılan hastalarda istatistiksel olarak anlamlı derecede daha yüksek idi (\%82,2'ye karş1 \%68,9). Prone pozisyonda komplikasyon izlenmeme oranının supine pozisyonda yapılan PNL'lere göre yüksek olmasının sebebi; supine $\mathrm{PNL}$ grubunda dahil edilen hastaların ilk kez bu teknikle PNL yapılan hastalar olmasıdır. Her iki merkezde de uzun zaman boyunca sadece prone pozisyonda PNL yapılmıştır. Bu nedenle prone pozisyonda PNL hakkında her iki merkezde oldukça yüksek tecrübeye sahiptir. Buna karışık supine PNL yapılan olgular bu pozisyonda PNL yapılan ilk olgulardır. $\mathrm{Bu}$ nedenle supine pozisyonda komplikasyon görülmeme oranı diğer gruba göre daha düşük 
çıkmıştır.

Sonuç olarak, böbrek taşlarının tedavisinde supine ve prone pozisyonlar benzer taşsızlık oranı, hastanede kalış süresi ve kanama oranlarına sahiptir. Prone pozisyonda yapılan PNL'ye göre supine pozisyonda yapılan PNL cerrahisi yaklaşık 15 dakika daha k1sa sürmektedir. Ancak supine pozisyonda komplikasyon oranı nispeten daha fazladır. Belirli bir vaka tecrübesine erişildikten sonra

\section{KAYNAKLAR}

1. Assimos D, Krambeck A, Miller NL, et al. Surgical management of stones: American Urological Association/Endourological Society Guideline, PART II. J Urol. 2016; 196:1161-1169.

2. Turk C, Petrik A, Sarica K, et al. EAU Guidelines on Diagnosis and Conservative Management of Urolithiasis. Eur Urol. 2016; 69:468-474.

3. Fernstrom I, Johansson B. Percutaneous pyelolithotomy. A new extraction technique. Scand J Urol Nephrol. 1976; 10:257-259.

4. Valdivia JG, Lachares Santamaria E, Villarroya Rodriguez S, et al. Percutaneous nephrolithectomy: simplified technic (preliminary report). Arch Esp Urol. 1987; 40:177-180.

5. de la Rosette JJ, Tsakiris P, Ferrandino MN,Elsakka $\underline{\text { AM}}, \underline{\text { Rioja J }}$, Preminger GM. Beyond prone position in percutaneous nephrolithotomy: A comprehensive review. Eur Urol. 2008; 54:1262-1269.

6. Valdivia JG, Scarpa RM, Duvdevani M, et al. Supine versus prone position during percutaneous nephrolithotomy: a report from the clinical research office of the endourological society percutaneous nephrolithotomy global study. J Endourol. 2011; 25: 1619-1625.

7. Cracco CM, Scoffone CM. ECIRS (Endoscopic combined intrarenal surgery) in the Galdakaomodi ed supine Valdivia position: a new life for percutaneous surgery? World J Urol. 2011; 29: 821-827.

8. Gökce Mİ, Ibiş A, Sancı A, et al.Comparison of supine and prone positions for percutaneous supine pozisyonda yapilan PNL cerrahisinin komplikasyon oranlarında azalma beklemekteyiz.

\section{Conflict of interest:None Çıkar Çatışması: Yok}

nephrolithotomy in treatment of staghorn stones. Urolithiasis. 2017; 45: 603-608.

9. Patel RM, Okhunov Z, Clayman RV, Landman J. Prone Versus Supine Percutaneous Nephrolithotomy: What Is Your Position? Curr Urol Rep. 2017;18:26.

10. Falahatkar S, Mokhtari G, Teimoori M. An update on supine versus prone percutaneous nephrolithotomy: a meta-analysis. Urol J. 2016; 13: 2814-2822.

11. Yuan D, Liu $Y$, Rao $H$, et al. Supine versus prone position in percutaneous nephrolithotomy for kidney calculi: a meta-analysis. J Endourol. 2016; 30: 754763.

12. Astroza G, Lipkin M, Neisius A, et al. Effect of supine vs prone position on outcomes of percutaneous nephrolithotomy in staghorn calculi: results from the Clinical Research Ofice of the Endourology Society Study. Urology. 2013; 82: 1240-1244.

13. Al-Dessoukey AA, Moussa AS, Abdelbary AM, et al. Percutaneous nephrolithotomy in the oblique supine lithotomy position and prone position: a comparative study. J Endourol. 2014; 28: 1058-1063.

14. Sharma G, Jangid DK, Yadav SS, Mathur R, Tomar $\mathrm{V}$. Retro-renal colon: role in percutaneous access. Urolithiasis. 2015; 43: 171-175.

15. Tuttle DN, Yeh BM, Meng MV, Breiman RS, Stoller ML, Coakley FV. Risk of injury to adjacent organs with lower-pole fluoroscopically guided percutaneous nephrostomy: evaluation with prone, supine, and multiplanar reformatted CT. J Vasc Interv Radiol. 2005; 16: 1489-1892. 